\title{
MOBILE LEARNING IN HIGHER EDUCATION
}

\author{
Petra Bauer ${ }^{1,3}$, Christine Kolb ${ }^{3}$ and Jasmin Bastian ${ }^{2,3}$ \\ ${ }^{l} \mathrm{Dr}$. \\ ${ }^{2}$ Jun.-Prof. Dr. \\ ${ }^{3}$ Department of Educational Studies, Johannes Gutenberg University Mainz, Germany
}

\begin{abstract}
Mobile technologies are an important part of our daily life and we carry them with us all the time. Mobile learning is already used in informal and non-formal learning but in the context of formal learning, it is not much used, yet. The constant availability of learning content and integration in digital networks inspire new methods and concepts in the field of learning and teaching. Furthermore, more emphasis on learners is required, to understand how they are already using mobile devices to support their learning and to encourage their active participation in mobile learning in formal settings. This paper presents some of the work of the ERASMUS+ funded MINE project which has brought together lecturers and learners from a range of European institutions to help develop competencies for active mobile learning in higher education.
\end{abstract}

\section{KEYWORDS}

Mobile Learning, Higher Education, International Project, Learning Scenarios

\section{INTRODUCTION}

The use of mobile learning in Higher Education should also increase the participation of the learner in the learning process. Within this project, a curriculum for university teachers was developed to prepare university teachers with the competencies they need to implement mobile learning in their teaching. However, students also need some preparation, because many of them are not used to or do not have the competencies required to use mobile learning. Therefore, a second curriculum for students was developed within this project. The aim was to produce open educational resources (OER) in this process, to be used for mobile learning, but there will also be practical examples of mobile learning, which can be easily adapted for different contexts and subjects. The strategic partnership also included an intensive program. This was held as part of the MINE Project, at which the emerging curricula were explored by university teachers and students to help them develop their own competencies in mobile learning. All relevant documents and results of this project are published under the creative commons license. This paper presents selected scenarios of mobile learning in the context of higher education.

\section{MOBILE LEARNING}

Mobile learning is defined by the use of different mobile devices such as smartphones, tablets, and notebooks and also by the use of free and open knowledge resources (Gikas 2013). Besides, the development of an open feedback culture and new forms of performance assessments are important components (Sung 2016). In the area of formal learning at university, there is a need for pedagogic scenarios to encourage educators to use these new technologies (Hochschulforum Digitalisierung 2015). Farley (2015) suggests that educators will need to move beyond didactic approaches still frequently found in higher education. Social constructivist approaches have been advocated, along with the development of communities of practice to support educators (Cochrane 2012).

Taking into account this context, the European teaching and research project "MINE - Mobile Learning in Higher Education" aims to increase the use of mobile technologies in higher education and contribute to the development of teaching and learning scenarios in this field. 


\section{TEACHING AND LEARNING ACTIVITIES}

Teachers in higher education need to care not only about what they are teaching but also about how they are mediating the topics. The pedagogical scenarios were evolved in order to address the views of learners and teachers in creating a context where active learning can happen. As Traxler and Crompton (2015) point out, mobile devices present great challenges to education systems. In higher education, the use of technology to enhance teaching and learning is a topic increasingly spoken about but which still needs further implementation in practice. These scenarios are examples of practices that have already been developed by the participants in the MINE project and they intend to show that mobile learning is not just about mobile technologies but above all about pedagogy.

\subsection{Mobile Learning Scenarios}

From the perspective of higher education, a wide range of different learning scenarios can be used, starting from individual mobile learning units to virtual teaching. In our project work, the partners of the MINE Project developed and applied different mobile learning scenarios in their work with students at the universities. Examples for these scenarios are videos, weblogs, online survey tools, e-portfolios, collaborative learning tools and wikis.

\subsubsection{Video}

Videos are everywhere. We could say that they have been one of the dominant forms of media consumption in the last few decades. They are an integral part of our everyday life and we consume them through different kinds of media. Entertainment and learning are the main things we draw from them. Producing and distributing videos has become increasingly easy and popular. Since the digital revolution and the invention of the internet we are moving away from single made and expensive film production with big studios involved in private and individual video making. Sharing and producing has become so easy that in some cases video platforms like YouTube have replaced traditional television as we know it. A big part of those videos is not only for entertainment purposes but also for education. Millions of tutorials, "how-to", taped lessons have been uploaded and the number of informally learning students is rising accordingly. Therefore, using video in classes and seminars could be a great opportunity for both learners and teachers.

The benefit for teachers and students is that videos can be used as a creative and different way to present information. There are many ways and possibilities to integrate them into lectures. For example, watching them to start a discussion in class or using them in the context of a flipped classroom. Also, watching videos on a particular topic might be interesting for a deeper analysis to go beyond the surface and therefore provide deeper learning on a particular field of theory or research. In media education, the analysis of a children's educational programme can be analysed regarding learning theories that fit the targeted age group and give reasons to discuss whether this programme is suitable to learn something or if there are any alterations necessary. Videos could be provided in a Learning Management System (LMS) or on a video platform like YouTube or Vimeo. Students are able to watch videos at home, use them for preparation for a class or they can discuss it on an online platform, i.e. LMS. In this case, videos are easy to use and most of them are available for free.

Another possibility is for students to produce the video themselves. In this case, students can learn how to produce a video and they have to think about how to put special content in a video, how to tell a story and/or how to present particular content. In order to raise students' motivation, competitions could be established or joined, e.g. the European Educational Video Challenge ${ }^{1}$ (EDIT). Every year, students are invited producing educational videos in form of a hackathon event with a 72-hour deadline and particular criteria, i.e. a certain topic or the use of particular words or items. In general, teachers can enable students to work collaboratively during video projects and the output created by the students can be graded by the teacher. Students learn how to receive and provide information and how to present information in a different format.

\footnotetext{
${ }^{1}$ http://www.editvideochallenge.org
} 


\subsubsection{Weblog}

A blog is an easy-to-handle content management system. It is an informational website published on the World Wide Web, consisting of diary-style text entries, called posts. But it is also possible to publish pictures, audio and video files in blogs. Blogs can be the work of a single individual, a small group or a large number of authors. Usually, they cover a single subject or topic. The authors keep records, write down logs, notes or thoughts. The posts are typically displayed in reverse chronological order, so that the most recent post appears first, at the top of the web page. So, a blog is used for storing notes, providing access to information, thoughts or experiences, furthermore, the commentary function allows a kind of communication between readers and author.

They can be used in different learning scenarios. The three main types of application are information storage, reflection medium or discourse, and publication medium. Depending on the context of the application, blogs can support formal and informal learning situations. In formal learning scenarios, blogs can be used as a learning content management system. Here, students and teachers can collect and summarise the content. It could also be a possibility to support virtual seminars or lessons. In this case, literature or videos could be provided and collected on a blog. In informal learning scenarios, blogs are used as personal journals or public (learning) diaries, as a feedback medium or as a medium for the learning of knowledge in general. Private weblogs can provide access to people, establish communities, and encourage mutual exchange in communities. A blog tool which could be used in courses is Wordpress ${ }^{2}$.

\subsubsection{Online Survey Tools: Kahoot!, Socrative and Mentimeter}

Although many online survey tools like Kahoot! ${ }^{3}$, Socrative $e^{4}$ and Mentimeter ${ }^{5}$ are becoming increasingly popular in higher education, they are still not utilised as often. Kahoot is generally known for its gamification aspect because it provides a variety of quizzes for use in class. You can also add and create own quizzes. Socrative is a tool that is typically used to conduct polls during lessons. Consisting of one teacher and one student version (app and web version available) small polls can be conducted within a few minutes. Teachers instantly get live results, which are anonymous and can be exported or converted into various types of files while students get instant feedback. Mentimeter is similar to Socrative in many ways but it is specifically tailored towards use in presentations. When you want to present something via Powerpoint Mentimeter will integrate with your presentation and enable participants to take a survey at specific points in your presentation.

\subsection{Mobile Collaboration}

Within the MINE Project, different online and offline tools in mobile learning were experienced and shared. During an intensive program in Lisboa, a Wiki was constructed and a lecture course, the mobile learning online week, was created to cooperate with teachers and students. All guidance and experiences are resumed in the MINE handbook.

\subsubsection{Wiki}

MINE-Wiki ${ }^{6}$ is an online knowledge network that can be managed and extended by MINE participants. The wiki provides a platform for those who are interested in learning the individual scenarios offered by MINE. On this page, you will also find information about the partners of the project and partner institutions. Above all, you will learn more about the team behind the project on MINE-Wiki. Other subcategories presented on this page are the mobile learning scenarios, under which, for example, the categories video, blog or collaborative learning are linked. Another point is the MINE curriculum: There you will find administrative information about the MINE project. In addition to that, you can find the exact course of the MINE week in Lisbon 2018 to get an impression of a past practical implementation of the project.

\footnotetext{
2 https://de.wordpress.com/

${ }^{3}$ https://kahoot.it/

${ }^{4}$ https://www.socrative.com/

${ }^{5}$ https://www.mentimeter.com/

${ }^{6} \mathrm{http}: / /$ wiki.mine-project.eu/Main_Page
} 


\subsubsection{Mobile Learning Week}

Mobile Learning combines learning in an international group. The content refers to mobile learning in higher education. The participants will be shown, discuss and reflect on various scenarios on how to use mobile tools in higher education. Each evening from 7 pm - 9 pm will be a live online learning session, experts from all over Europe will show the participants interesting tools and solutions. There is the possibility to get in contact with other students and teachers. The users get to know other learning traditions and cultures. This makes them experts in state of the art educational technologies and didactic approaches.

The mobile learning week combines blended learning arrangements with online and offline learning experiences. The learning system links problem-oriented workshops with phases of self-directed learning set up on web-based training and communication via a learning management system in line with requirements (Kuhmann \& Sauter 2008, p. 101). In these learning scenarios, analogue and digital learning content merge. The participants can use networking with other participants to arrange self-directed learning networks.

Blended Learning in the online week focuses on the virtual classroom that takes place daily and in which all participants take part. There they learn new learning contents through the tutors and come into direct contact with the experts of the week. After these online events, the participants return to their self-learning phase and work out learning tasks that have been put right for them. During this time they can get in contact with the other learners at any time. The focus of these blended learning scenarios during Mobile Learning Week is the intercultural exchange between learners. They can exchange their learning experiences online and find solutions to problems together. In 2020 the online week will take place from 20th April till the 25th of April.

\subsubsection{MINE Handbook}

Through the use of new learning methods in university teaching new opportunities and challenges arise. The MINE Handbook is a storybook by teachers and students sharing their experiences about using mobile learning in higher education. The goal of the MINE project was not to develop new applications but to test and evaluate existing solutions in a wide variety of learning scenarios. The M-learning handbook gives an overview of the project, mobile learning scenarios and summarises stories and opinions by teachers, colleagues, and students. It encourages the reader with some success stories to try out new things and thus tread new paths in the area of university teaching. Furthermore, it views different mobile learning scenarios by taking a closer look at benefits for teachers and learners, goals and expected outcomes, possible options for application technical parts and finally pedagogical added values. The pedagogical practice is important if the digital education revolution will be more than rhetoric and will offer students better learning opportunities. Using mobile tools proactively, it can facilitate self-regulated learning and learners are placed in their roles as active actors, the self-controlled their learning process, independently and competently determine the use of the technologies in the centre. The MINE Handbook will be provided online and in a printed version in the first quarter of 2020.

\section{STRATEGIC PARTNERSHIP}

The three-year MINE project was funded by Erasmus+ and realised within the framework of a strategic partnership between six European universities: University of Education Upper Austria, Linz, Austria; University of Aberdeen, UK; Universidade Aberta, Lisbon, Portugal; Tallinn University, Estonia; Rhodes University, Greece; Johannes Gutenberg University Mainz, Germany.

All relevant documents and results of this project are published under the creative commons license and available to be downloaded from the project website (http://www.mine-project.eu/).

\section{REFERENCES}

Cochrane, T., 2012. Critical success factors for transforming pedagogy with mobile Web 2.0. British Journal of Educational Technology, [online] https://doi.org/10.1111/j.1467-8535.2012.01384.x [28.10.2019].

Farley, H. et al., 2015. How Do Students Use Their Mobile Devices to Support Learning? A Case Study from an Australian Regional University. Journal of Interactive Media in Education. 2015 (1), p. Art. 14. http://doi.org/10.5334/jime.ar [28.10.2019]. 
Gikas, J. M.M., 2013. Grant Mobile Computing Devices in Higher Education: Student Perspectives on Learning with Cellphones, Smartphones \& Social Media. [online] http://www.sciencedirect.com/science/article/pii/S10967516130 002 62. [27.02.2017].

Hochschulforum Digitalisierung, 2015. Diskussionspapier. 20 Thesen zur Digitalisierung der Hochschulbildung, [online] https://hochschulforumdigitalisierung.de/sites/default/files/dateien/HFD\%20AP\%20Nr\%2014_Diskussionspapier.pdf [27.02.2016].

Kuhmann, M. Annette \& Sauter, Werner, 2008. Innovative Lernsysteme: Kompetenzentwicklung mit Blended Learning und Social Software, Springer-Verlag Berlin, Heidelberg.

Sung, K. E., Chang, T. C. Liu, 2016. The effects of integrating mobile devices with teaching and learning on students' learning performance: A meta-analysis and research synthesis, Computers \& Education, 94, 252-275.

Traxler, J. \& Crompton, H., 2015. Mobile Learning In The UK Today: Successes, Failures, Future, GLOKALde April 2015, Vol. 1, No. 2 